\title{
A Fuzzy Logic Approach to Model and Predict HV Cable Insulation Behaviour under Thermal Aging
}

\section{Lakhdar Bessissa $^{1}$, Larbi Boukezzi ${ }^{2}$, Djillali Mahi $^{1}$}

1 Laboratory of Studies and Development of Semiconductor and Dielectric Materials, LeDMaScD, University Amar Telidji of Laghouat, BP 37G route of Ghardaïa, Laghouat 03000, Algeria bsisa.lakhdar@email.univ-djelfa.dz,d.mahi@mail.lagh-univ.dz

2 Materials Science and Informatics Laboratory, MSIL, University Ziane Achour of Djelfa, BP 3117 route of Moudjbara, Djelfa 17000, Algeria lboukezzi@email.univ-djelfa.dz

\begin{abstract}
Given the non-linearity of changes in the dielectric and mechanical properties of insulation, it is difficult to find neither a theoretical nor an experimental model for the aging mechanism. Hence, the need to model the evolution of mechanical properties of the XLPE material under thermal aging using new methods is necessary. The use of fuzzy logic is one of these methods and presents an original idea in high voltage prediction problems. Several factors were considered, namely the aging time and the level of applied temperature. The study of the impact of these parameters on the quality of the fuzzy algorithm is carried out. The characteristics of the modelling function (trapezoidal or triangular) and the number of membership functions partitions was also taken into consideration. The obtained results were encouraging. It has been proved that fuzzy logic is a powerful tool that can be used in predicting the properties of insulation. Furthermore, the analytical findings were in good agreement with the experimental results with an acceptable error margin.
\end{abstract}

Keywords: Thermal aging; Crosslinked polyethylene (XLPE); Fuzzy logic; Fuzzy Inference System (FIS); Number of partitions

\section{Introduction}

Electrical power systems include a large number of expensive and important high voltage cables of different ages, manufactured and mounted during decades. Repair and replacement of important cable system are expensive and correct scheduling for those, would give large saving of costs. Insulation system of high voltage power cable and their accessories are subjected to different kind of stress 
during their life, and thus to degradation and deterioration. These can lead to a reduction of life and so to a lower reliability of electrical power systems [1, 2]. Now that such insulating materials have been in service for several decades the opportunity exists to ascertain their current condition so that decisions can be taken regarding replacement.

The great importance of XLPE as insulation encourages researchers in laboratories through the world to investigate a lot of experimental techniques in order to get more information and characterize well the degradation mechanisms of the material under service conditions. Recent investigations aimed with the effect of thermal and electrical stresses on the endurance capability of the insulation materials [3], degradation mechanisms of insulation cable materials under thermal and radiation aging [4] and the effect of water tree aging on the properties of cables insulation [5]. These investigations are costly and time consuming. They need sometimes few years to get sufficient database to solve economical problems of energy and making maintenance in a simplest way. This obstacle forces researchers to find powerful modelling methods to solve this problem. Recently, several intelligent systems have been developed which help scientist and engineer to use in efficient way the database and get with more precision future states of the insulation system. Among these intelligent systems, artificial neural networks (ANN) and fuzzy logic (FL) present a powerful tools to predict and diagnosis high voltage insulation materials. In recent studies, a novel extension neural network algorithm was used in recognition of partial discharge pattern in high voltage power apparatus [6]. Other application aimed with classification and diagnostic of transformer oil [7]. However a small amount of papers aimed with applying of FL in high voltage field can be found [8].

The objective of this work is to develop a fuzzy logic algorithm using the nonlinear properties variations of the material versus aging time and for different thermal constraint values, to predict XLPE insulation behaviour when the learning time is clearly less than the laboratory test time. We shall note that the use of FL in this paper presents an original idea in high voltage prediction problems. This study treats also the impact of the modelling function characteristics (trapezoidal or triangular) and the number of membership functions partitions on the quality of the fuzzy algorithm. Parts of the obtained results are recently presented in several international conferences $[9,10]$.

\section{Experimental Setup}

The used material is XLPE UNION CARBIDE 4201 which is used as an insulator in medium and high voltage cables. Plates of $2 \mathrm{~mm}$ thickness were moulded using a heat press machine. According to the International Electrotechnic Committee (IEC) 540 publication [11], dumbbell shape samples of $7.5 \mathrm{~cm}$ length were cut and 
will be performed to mechanical tests. The thermal aging experiments were carried out in the forced air ventilating oven which can maintain the average temperature of sample within $\pm 2^{\circ} \mathrm{C}$. Three temperatures have been considered namely $80^{\circ} \mathrm{C}, 100^{\circ} \mathrm{C}$ and $120^{\circ} \mathrm{C}$. The full aging time is 5000 hours for $80^{\circ} \mathrm{C}$ and $100^{\circ} \mathrm{C}$ and 2500 hours for $120^{\circ} \mathrm{C}$. After each $500 \mathrm{~h}$ aging time, 10 samples were taken, and then subjected to tensile stress. The experiments consist in breaking the sample, at ambient temperature, using a dynamometer which moves with speed of $50 \mathrm{~mm} / \mathrm{min}$. This test allows us to measure the tensile strength of the material. The variation of tensile strength according to aging time is presented in Figure 1[12].

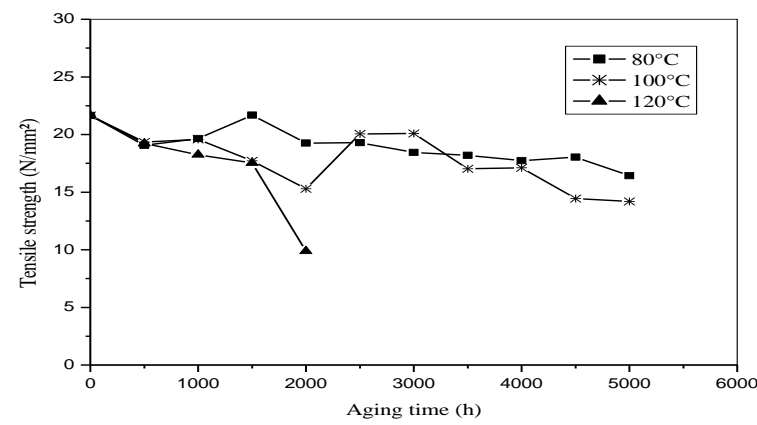

Figure 1

Variation of the tensile strength in function of the aging time

This figure shows that tensile strength decreases as a function of aging time. This decrease is even more pronounced as the temperature is higher. The mechanisms which are responsible for this depletion are generally the thermo-oxidative degradation, the chains' break, the decrease of the crosslinking degree and the variation in the crystallinity degree. For aging temperatures $80^{\circ} \mathrm{C}$ and $100^{\circ} \mathrm{C}$, this property is stored and remains substantially higher than the lower limit value (12.5 $\mathrm{N} / \mathrm{mm}^{2}$ ) required by IEC 502 [13]. However, for other temperatures, the degradation was reached after relatively short time.

\section{Modelling and Prediction by Fuzzy Logic}

\subsection{Fuzzy Logic}

The concept of "fuzzy set" was preliminarily introduced by Zadeh [14, 15], who pioneered the development of fuzzy logic (FL) replacing Aristotelian logic which has two possibilities only. Zadeh has motivated his work on FL with the observation that the key elements in human thinking are not numbers but levels of fuzzy sets $[15,16]$. Fuzzy approach performs numerical computation by using 
linguistic labels stimulated by membership functions. In the learning process, membership functions characterize the fuzziness in a fuzzy set, whether the elements in the set are discrete or continuous in a graphical form for eventual use in the mathematical formalism of fuzzy set theory [17, 18]. Although FL was brought forward by Zadeh [14, 15] in 1965, fuzzy concepts and systems attracted attention after a real control application in 1975 conducted by Mamdani and Assilian $[15,19,20]$. For control applications, fuzzy logic operations that include comparison of two or more membership functions are needed [21]. Figure 2 shows a typical membership function for small, medium and large class sizes in a universe $\mathrm{U}$.

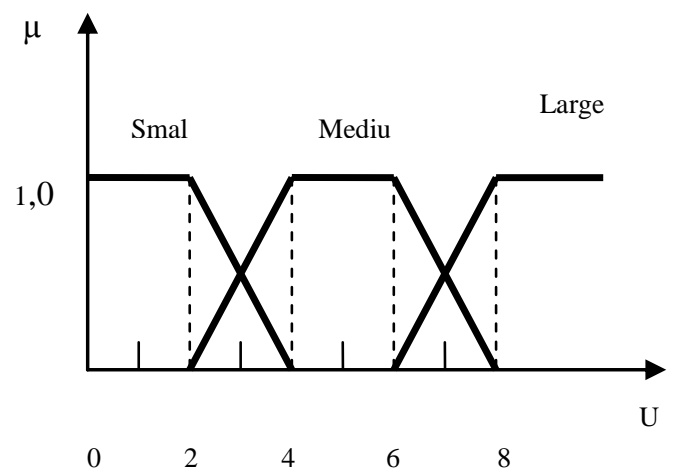

Figure 2

Fuzzy subsets

\subsection{Fuzzy Inference System}

Basically, a fuzzy inference system is composed of five functional blocks as follows [22, 23]:

(i) A rule base containing a number of fuzzy IF-THEN rules. The general form of a fuzzy IF-THEN rule is as follows; Rule: IF Z is A THEN F is B.

(ii) A database, which defines the membership functions of the fuzzy sets used in the fuzzy rules.

(iii) A decision-making unit, which performs the inference operations on the rules.

(iv) A fuzzification inference, which transforms the crisp inputs into degree of match with linguistic values.

(v) A defuzzification inference, which transforms the fuzzy results of the inference into a crisp output. These functional blocks are shown in Figure 3. 


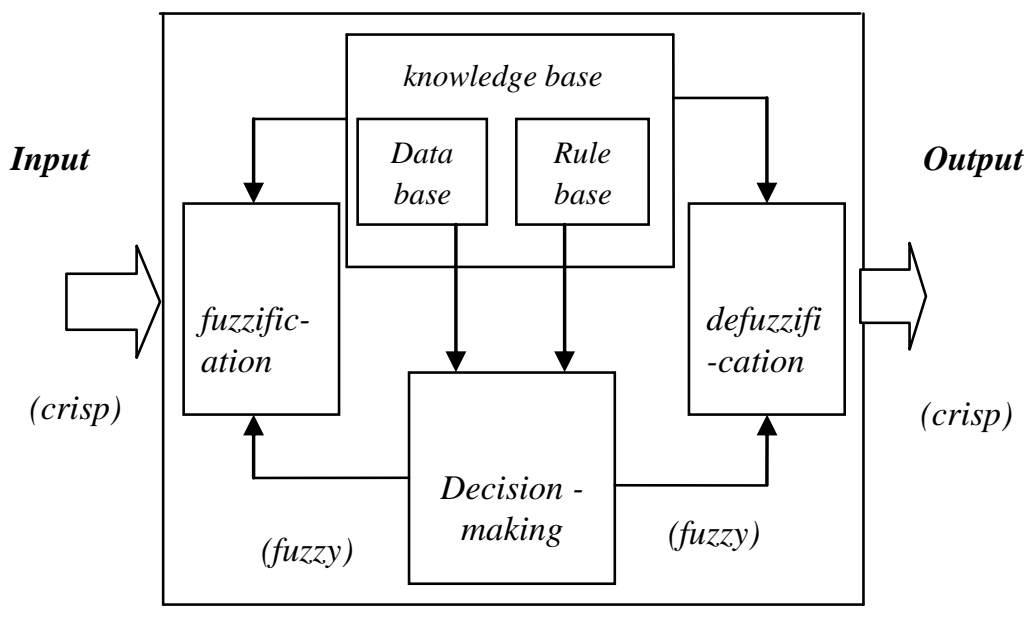

Figure 3

Block diagram for a fuzzy inference system

\subsection{Modelling and Prediction}

In our case, the input fuzzy variables are: the level of temperature $\mathrm{T}$ which takes $80{ }^{\circ} \mathrm{C}, 100{ }^{\circ} \mathrm{C}$ and $120^{\circ} \mathrm{C}$ as values, and the aging time t. The output variable is the tensile strength.

Three fuzzy labels were attributed to the variations of these variables and various combinations were distinctively created:

Case 1: 3 fuzzy sets were created, S, M and L, which means that the variations are respectively Small, Medium or Large.

Case 2: 6 fuzzy sets were created: SS, SL, MS, ML, LS and LL, which means that the changes are Small-Small, Small-Large, Medium-Small, MediumLarge, Large-Small or Large-Large.

Case 3: 9 fuzzy sets were created: SS, SM, SL, MS, MM, ML, LS, LM and LL, which means that variations are Small-Small, Small-Medium, SmallLarge, Medium-Small, Medium-Medium, Medium-Large, Large-Small, Large-Medium or Large-Large.

Membership functions can take any form. In our case, for reasons of simplification of the calculations, we have used two kinds of functions: trapezoidal and trapezoidal-triangular.

The fuzzification is to evaluate the used membership functions. Each fuzzy set is characterized by a degree of membership $\mu$ which represents the degree of truth of the membership function as shown in Figure 4. 


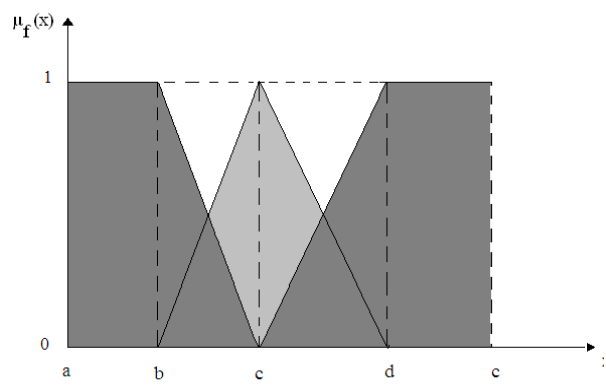

(a)

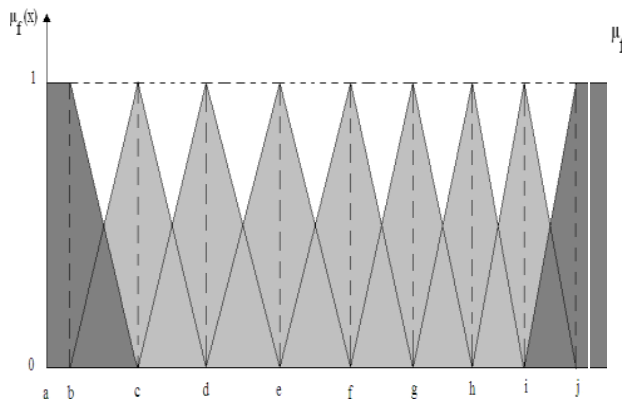

(c)

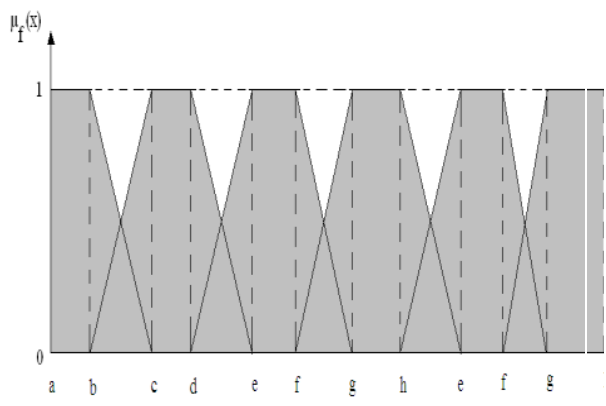

(e)

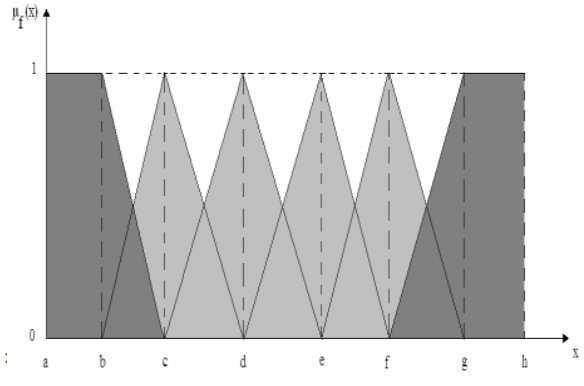

(b)

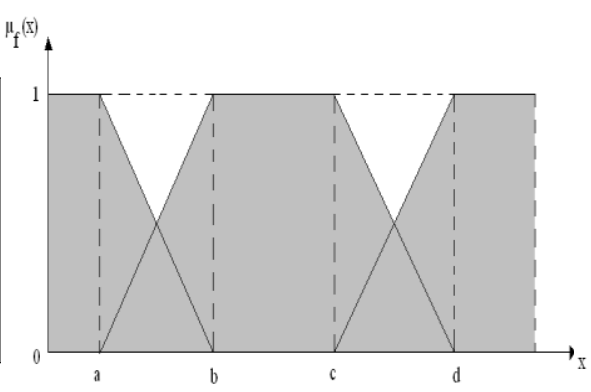

(d)

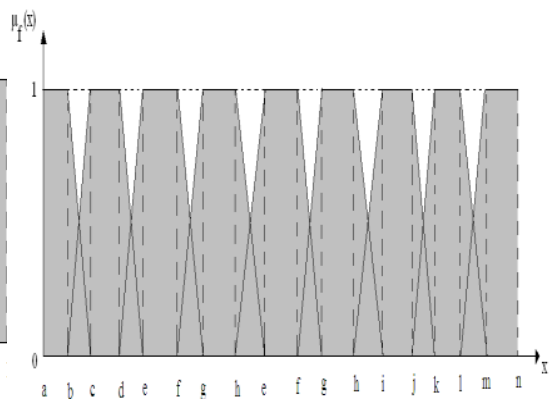

(f)

Figure 4

The membership functions of input / output system variables: (a) mixed membership function with 3 partitions, (b) mixed membership function with 6 partitions, (c) mixed membership function with 9 partitions, (d) trapezoidal membership function with 3 partitions, (e) trapezoidal membership function with 6 partitions, (f) trapezoidal membership function with 9 partitions. 
The fuzzy system used in this work is a Mamdani type we have used the temperature and the aging time as input variables and tensile strength as output variable. Tables 1, 2 and 3 present the fuzzy inference system and gives the fuzzy rules presented in following type: IF "Condition 1" AND "Condition 2" Then "Condition 3"

Table 1

Matrix inference functions for three partitions

\begin{tabular}{|c|c|c|}
\hline \multicolumn{2}{|c|}{ Output } & Tensile strength \\
\hline \multirow{3}{*}{ Input } & & $\mathrm{L}$ \\
\cline { 2 - 3 } & $\mathrm{S}$ & $\mathrm{M}$ \\
\cline { 2 - 3 } $\mathbf{t}$ & $\mathrm{M}$ & $\mathrm{S}$ \\
\hline
\end{tabular}

Table 2

Matrix inference functions for six partitions

\begin{tabular}{|c|c|c|}
\hline \multicolumn{2}{|c|}{ Input } & Tutput \\
\hline \multirow{7}{*}{} & $\mathrm{SS}$ & $\mathrm{LL}$ \\
\cline { 2 - 3 } & $\mathrm{SL}$ & $\mathrm{LS}$ \\
\cline { 2 - 3 } & $\mathrm{MS}$ & $\mathrm{ML}$ \\
\cline { 2 - 3 } & $\mathrm{ML}$ & $\mathrm{MS}$ \\
\cline { 2 - 3 } & $\mathrm{LS}$ & $\mathrm{SL}$ \\
\cline { 2 - 3 } & $\mathrm{LL}$ & $\mathrm{SS}$ \\
\hline
\end{tabular}

Table 3

Matrix inference functions for nine partitions

\begin{tabular}{|c|c|c|}
\hline \multicolumn{1}{|c|}{ Input } & Tensile strength \\
\hline \multirow{4}{*}{} & $\mathrm{SS}$ & $\mathrm{LL}$ \\
\cline { 2 - 3 } & $\mathrm{SM}$ & $\mathrm{LM}$ \\
\cline { 2 - 3 } & $\mathrm{SL}$ & $\mathrm{LS}$ \\
\cline { 2 - 3 } & $\mathrm{MS}$ & $\mathrm{ML}$ \\
\cline { 2 - 3 } & $\mathrm{MM}$ & $\mathrm{MM}$ \\
\cline { 2 - 3 } & $\mathrm{ML}$ & $\mathrm{MS}$ \\
\cline { 2 - 3 } & $\mathrm{LS}$ & $\mathrm{SL}$ \\
\cline { 2 - 3 } & $\mathrm{LM}$ & $\mathrm{SM}$ \\
\cline { 2 - 3 } & $\mathrm{LL}$ & $\mathrm{SS}$ \\
\hline
\end{tabular}


The conditions being dependant between them by a logical operator AND, the degree of membership function, which is the conclusion, will be then equal for least two degrees of membership conditions. The membership's functions of output are built by aggregations of membership functions obtained by the rules in whole. For example, the degree of membership function of output (tensile strength) will be calculated three, six and nine times since there are exactly three, six and nine rules that arrive at this conclusion; one thus calculates the maximum between these membership functions. To calculate the numerical value of membership functions of output from the linguistic variables, we have used the gravity center method.

\section{Results and Discussion}

To model the behaviour of high voltage insulation, we need a long time to have a complete test database to give a good prediction. The use of fuzzy logic in modelling of insulators properties under thermal aging is economic and reduces the aging time. The work carried out consists of modelling and prediction of the XLPE properties under thermal aging. The experimental results of tensile strength under thermal aging [11] were used to build up the fuzzy rules and also for introducing a fuzzy inference system (FIS) in the prediction. Modelling of the chosen property is done for the entire interval of experiments which gives us a possibility to validate the developed fuzzy model. For $80^{\circ} \mathrm{C}$ and $100^{\circ} \mathrm{C}$ the experiments time is going up until $5000 \mathrm{~h}$ and for $120^{\circ} \mathrm{C}$ it reaches $2000 \mathrm{~h}$. However, in the prediction phase the model gives the values of the property for aging times not reached by experiments.

Figure 5 presents the results of the tensile strength modelling in the case of $80^{\circ} \mathrm{C}$ as temperature of aging. In Figure 5 (a) we have represented the modelling results using the trapezoidal function with different partitions compared with the experimental results. The results of the use of mixed function (trapezoidal and rectangular) are presented in Figure 5 (b). Similar presentation as $80^{\circ} \mathrm{C}$ has been presented in the case of other aging temperatures (Figure 6 for $100^{\circ} \mathrm{C}$ and Figure 7 for $120^{\circ} \mathrm{C}$ ).

From the obtained results, it is clear that fuzzy logic has great power to solve modelling problems in high voltage cables field. The chosen trapezoidal and mixed shape of the membership functions give good representations of linguistic variables. In Figures 5 and 6 where the variations of the tensile strength are not monotone and present some peaks at the beginning of aging times, the experimental curve is not reproduced closely by fuzzy model. The non ability of fuzzy logic to reproduce non monotone function is one of the most limitations of this modelling method. However when the XLPE property presents a monotone variation, as in the case of $120^{\circ} \mathrm{C}$ (Figure 7), the curves generated by the fuzzy model reproduce in a manner that is very close to the experimental results. 
In order to test the developed FL model, we have divided the used experimental results into training and testing parts. Herein, $60 \%$ of experimental data were used for training, whereas $40 \%$ ones were employed for testing. The testing step is done in two different ways. First, we choose the training and the testing points in alternating way. Second, we take the first $60 \%$ of points to train the model and the last $40 \%$ of data for testing.

In Table 4, we have presented the medium and maximum relative errors for training and the first case of testing (alternating way). In this Table, we have also taken into consideration all proposed membership. If we choose the medium relative error as criterion of comparison, the trapezoidal function gives the best results. Moreover, in the almost cases (in the case of aging temperatures $100^{\circ} \mathrm{C}$ and $120^{\circ} \mathrm{C}$ ), the model which use six partitions gives the best results and presents a minimum value of medium relative error. For $80^{\circ} \mathrm{C}$, the medium relative errors in training and testing phases were found equal to $4.35 \%$ and $1.69 \%$, respectively. For $100^{\circ} \mathrm{C}$, also in the training and testing phases, the medium relative errors were determined as $4.52 \%$ and $10.01 \%$, respectively. In the case of $120^{\circ} \mathrm{C}$, the training is done with $0.5 \%$ as medium relative error, and the testing is achieved with $0.16 \%$ as medium relative error.

In Table 5, we present the similar analysis results as Table 4 but for the second case of testing. In this case, the best result of prediction at $80^{\circ} \mathrm{C}$ is obtained with mixed membership function and six partitions. However, for $100^{\circ} \mathrm{C}$ the best result is obtained with always mixed membership function but with three partitions. In the case of $120^{\circ} \mathrm{C}$, the best result of prediction is obtained with trapezoidal membership function and six partitions. In terms of medium relative error, it reaches $3.77 \%$ in the training phase and $2.26 \%$ in testing phase. These results concern the aging temperature $80^{\circ} \mathrm{C}$. At $100^{\circ} \mathrm{C}$, the medium relative errors are $8.97 \%$ and $6.6 \%$ for training and testing respectively. In the case of $120^{\circ} \mathrm{C}$, medium relative errors reach $0.53 \%$ and $0.2 \%$ for training and testing respectively.

\section{Thermal Endurence of XLPE}

It is crucial to the operator to know the changes in material properties resulting from prolonged exposure to high operating temperatures in order to ensure that the material exhibits throughout his life, the minimum properties required in its use [24]. In this section, fuzzy logic was applied to predict the behaviour of the cable insulation under thermal operating conditions for longer period of aging more than the experimental interval. The used fuzzy model gives the best results in the modelling step discussed in the preceding section. This model uses trapezoidal form of function and six partitions. XLPE tensile strength is predicted for an aging time of 9500 hours for temperatures of $80^{\circ} \mathrm{C}$ and $100^{\circ} \mathrm{C}$, and an aging time of 3500 hours for temperature of $120^{\circ} \mathrm{C}$. The obtained results are summarized in 
Figure 8. This figure is used to determine the XLPE lifetime for a decrease of $50 \%$ from the initial value of the characteristic in question. This limit is considered to be the criterion of material end life [12].

Figure 9 is used to calculate the temperature values for each level of aging time. By extrapolation of the thermal endurance graph to life length of 20000 hours [11, 24], the index temperature is deduced to be $78.82^{\circ} \mathrm{C}$ (Table 6). The obtained value is slightly higher than that found in literature [25] via conventional method.

Table 4

Comparison of experimental results with training and testing results of Fuzzy logic model (first case)

\begin{tabular}{|c|c|c|c|c|c|c|c|c|c|c|}
\hline & $\begin{array}{c}\text { Applied } \\
\text { temperature }\end{array}$ & \multicolumn{3}{|c|}{$80^{\circ} \mathrm{C}$} & \multicolumn{3}{|c|}{$100^{\circ} \mathrm{C}$} & \multicolumn{3}{|c|}{$120^{\circ} \mathrm{C}$} \\
\hline & $\begin{array}{l}\text { Type of } \\
\text { membership } \\
\text { function }\end{array}$ & \multicolumn{9}{|c|}{ Mixed } \\
\hline & $\begin{array}{l}\text { Number of } \\
\text { partitions }\end{array}$ & 3 & 6 & 9 & 3 & 6 & 9 & 3 & 6 & 9 \\
\hline \multirow{2}{*}{ Testing } & $\begin{array}{c}\text { Medium relative } \\
\text { error }(\%)\end{array}$ & 2,38 & 1,96 & 1,69 & 11,11 & 10,98 & 10,38 & 9,73 & 5,92 & 3,7 \\
\hline & $\begin{array}{c}\text { Maximum relative } \\
\text { error }(\%)\end{array}$ & 2,99 & 2,47 & 2,52 & 17,58 & 19,22 & 20 & 9,73 & 5,92 & 3,7 \\
\hline \multirow[t]{4}{*}{ Training } & $\begin{array}{c}\text { Medium relative } \\
\text { error }(\%)\end{array}$ & 5 & 4,77 & 4,4 & 6,43 & 5,14 & 4,76 & 17,52 & 11,50 & 7,65 \\
\hline & $\begin{array}{c}\text { Maximum relative } \\
\text { error }(\%)\end{array}$ & 12,63 & 12,13 & 12,49 & 12,42 & 11,32 & 10,62 & 31,00 & 20,77 & 13,78 \\
\hline & $\begin{array}{l}\text { Type of } \\
\text { membership } \\
\text { function }\end{array}$ & \multicolumn{9}{|c|}{ Trapezoidal } \\
\hline & $\begin{array}{l}\text { Number of } \\
\text { partitions }\end{array}$ & 3 & 6 & 9 & 3 & 6 & 9 & 3 & 6 & 9 \\
\hline \multirow{2}{*}{ Testing } & $\begin{array}{c}\text { Medium relative } \\
\text { error }(\%)\end{array}$ & 3,33 & 1,96 & 1,69 & 11,28 & 10,93 & 10,01 & 9,9 & 0,16 & 13,1 \\
\hline & $\begin{array}{c}\text { Maximum relative } \\
\text { error }(\%)\end{array}$ & 5,19 & 2,36 & 2,60 & 19,41 & 19,93 & 20 & 9,9 & 0,16 & 13,1 \\
\hline \multirow[t]{2}{*}{ Training } & $\begin{array}{c}\text { Medium relative } \\
\text { error }(\%)\end{array}$ & 5,42 & 4,56 & 4,35 & 7,09 & 4,3 & 4,52 & 18,79 & 0,5 & 10,67 \\
\hline & $\begin{array}{c}\text { Maximum relative } \\
\text { error }(\%)\end{array}$ & 14,75 & 12,45 & 12,68 & 12,27 & 10,02 & 10,67 & 34,45 & 1,20 & 26,94 \\
\hline
\end{tabular}

Table 5

Comparison of experimental results with training and testing results of Fuzzy logic model (second case)

\begin{tabular}{|c|c|c|c|c|c|c|c|c|c|c|}
\hline & Applied temperature & \multicolumn{3}{|c|}{$80^{\circ} \mathrm{C}$} & \multicolumn{3}{|c|}{$100^{\circ} \mathrm{C}$} & \multicolumn{3}{|c|}{$120^{\circ} \mathrm{C}$} \\
\hline & $\begin{array}{l}\text { Type of membership } \\
\text { function }\end{array}$ & \multicolumn{9}{|c|}{ Mixed } \\
\hline & Number of partitions & 3 & 6 & 9 & 3 & 6 & 9 & 3 & 6 & 9 \\
\hline \multirow{2}{*}{ Testing } & $\begin{array}{c}\text { Medium relative error } \\
(\%)\end{array}$ & 2,39 & 2,26 & 2,45 & 6,6 & 7,53 & 8,07 & 31 & 20,77 & 13,78 \\
\hline & $\begin{array}{c}\text { Maximum relative } \\
\text { error }(\%)\end{array}$ & 5,66 & 6,21 & 6,76 & 11,63 & 14,46 & 15,5 & 31 & 20,77 & 13,78 \\
\hline \multirow[t]{2}{*}{ Training } & $\begin{array}{c}\text { Medium relative error } \\
(\%)\end{array}$ & 4,23 & 3,77 & 3,9 & 8,97 & 8,85 & 8,66 & 9,50 & 4,75 & 3,16 \\
\hline & Maximum relative & 12,63 & 12,13 & 12,49 & 16,86 & 19,80 & 20,2 & 19,12 & 12,5 & 8,33 \\
\hline
\end{tabular}




\begin{tabular}{|c|c|c|c|c|c|c|c|c|c|c|}
\hline & error (\%) & & & & & & & & & \\
\hline & $\begin{array}{l}\text { Type of membership } \\
\text { function }\end{array}$ & \multicolumn{9}{|c|}{ Trapezoidal } \\
\hline & Number of partitions & 3 & 6 & 9 & 3 & 6 & 9 & 3 & 6 & 9 \\
\hline \multirow{2}{*}{ Testing } & $\begin{array}{c}\text { Medium relative error } \\
(\%)\end{array}$ & 3,08 & 2,4 & 2,49 & 9,37 & 8,1 & 7,96 & 34,45 & 0,2 & 3,34 \\
\hline & $\begin{array}{c}\text { Maximum relative } \\
\text { error }(\%)\end{array}$ & 6,1 & 6,7 & 6,94 & 16,40 & 14,26 & 15,36 & 34,45 & 0,2 & 3,34 \\
\hline \multirow[t]{2}{*}{ Training } & $\begin{array}{c}\text { Medium relative error } \\
(\%)\end{array}$ & 5,47 & 3,67 & 3,89 & 9,22 & 8,44 & 8,74 & 8,31 & 0,53 & 13,1 \\
\hline & $\begin{array}{c}\text { Maximum relative } \\
\text { error }(\%)\end{array}$ & 14,75 & 12,45 & 12,68 & 18,43 & 19,80 & 20,39 & 19,52 & 1,20 & 26,94 \\
\hline
\end{tabular}

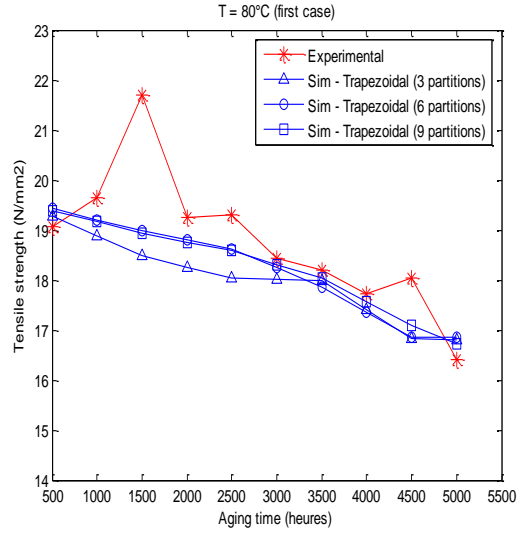

(a)

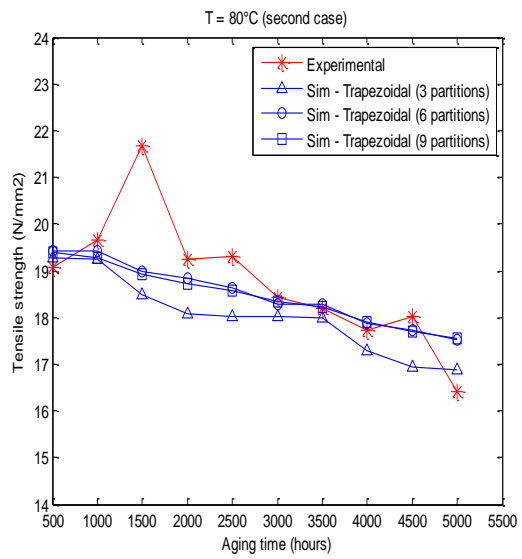

(c)

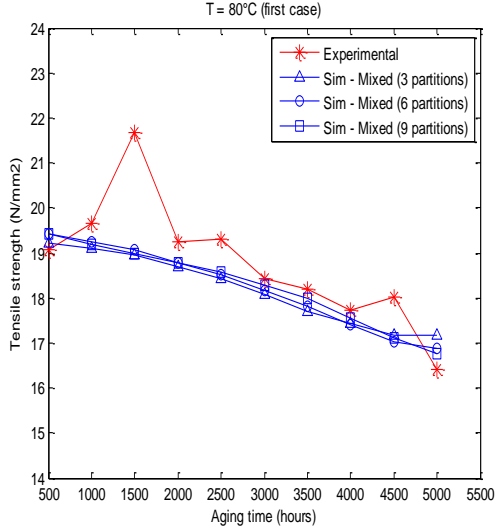

(b)

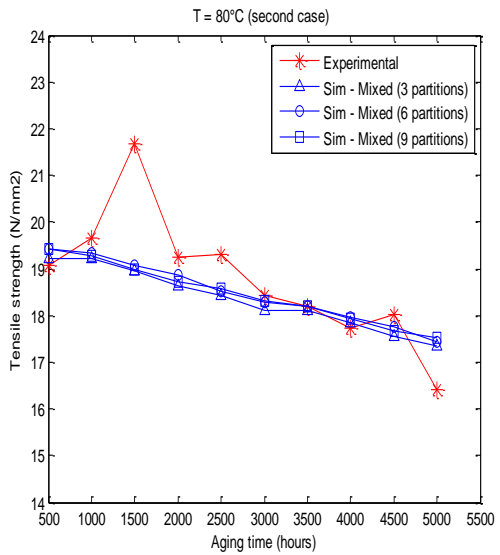

(d)

Figure 5

Modelling of tensile strength at $\mathrm{T}=80^{\circ} \mathrm{C}$ :

(a): Trapezoidal function (first case), (b): Mixed function (first case),

(c): Trapezoidal function (second case), (d): Mixed function (second case) 


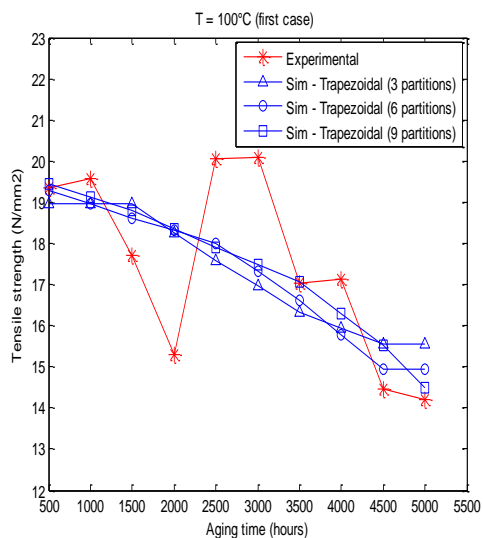

(a)

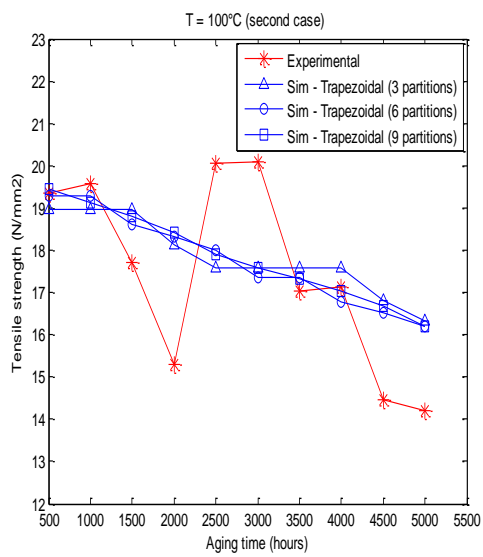

(c)

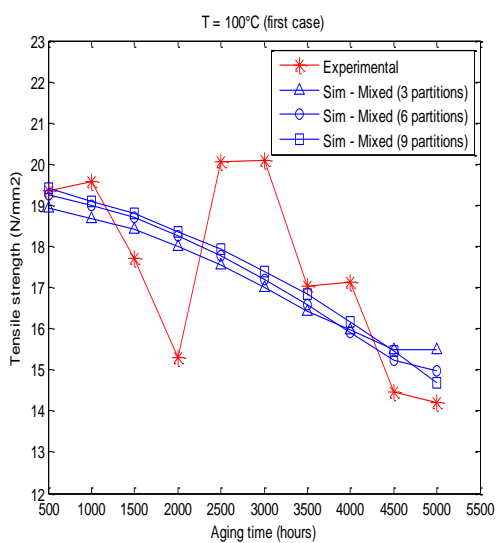

(b)

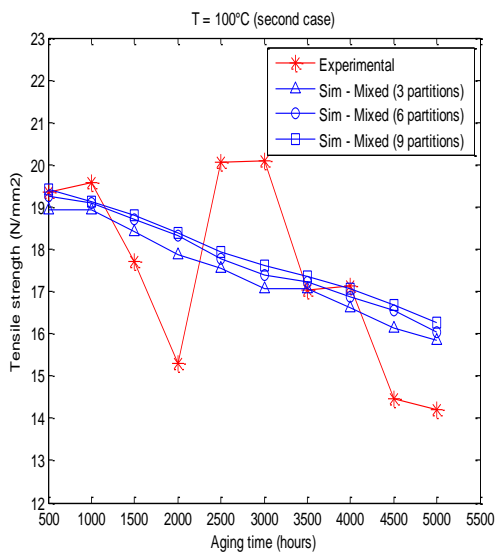

(d)

Figure 6

Modelling of tensile strength at $\mathrm{T}=100^{\circ} \mathrm{C}$ :

(a): Trapezoidal function (first case), (b): Mixed function (first case),

(c): Trapezoidal function (second case), (d): Mixed function (second case). 


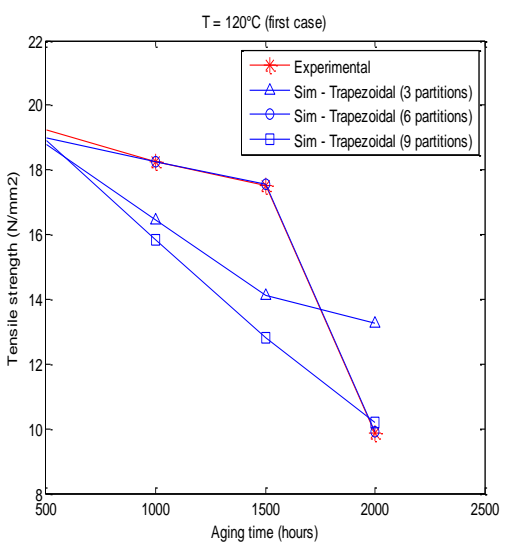

(a)

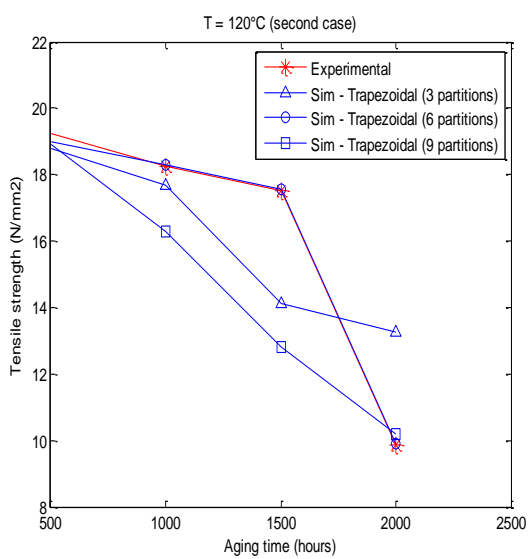

(c)

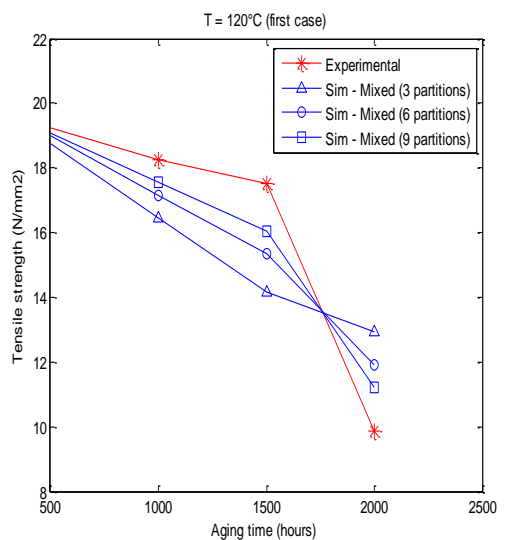

(b)

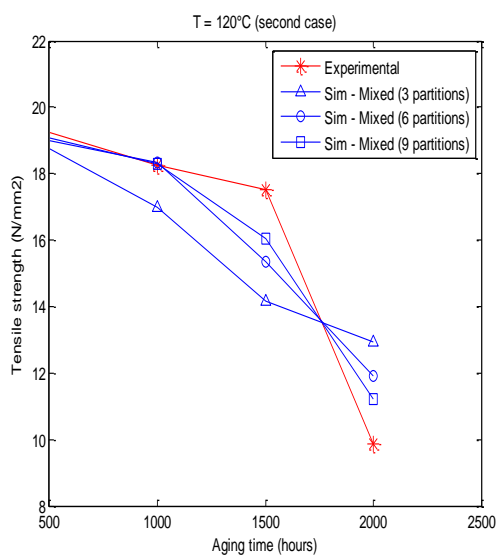

(d)

Figure 7

Modelling of tensile strength at $\mathrm{T}=120^{\circ} \mathrm{C}$ :

(a): Trapezoidal function (first case), (b): Mixed function (first case),

(c): Trapezoidal function (second case), (d): Mixed function (second case). 


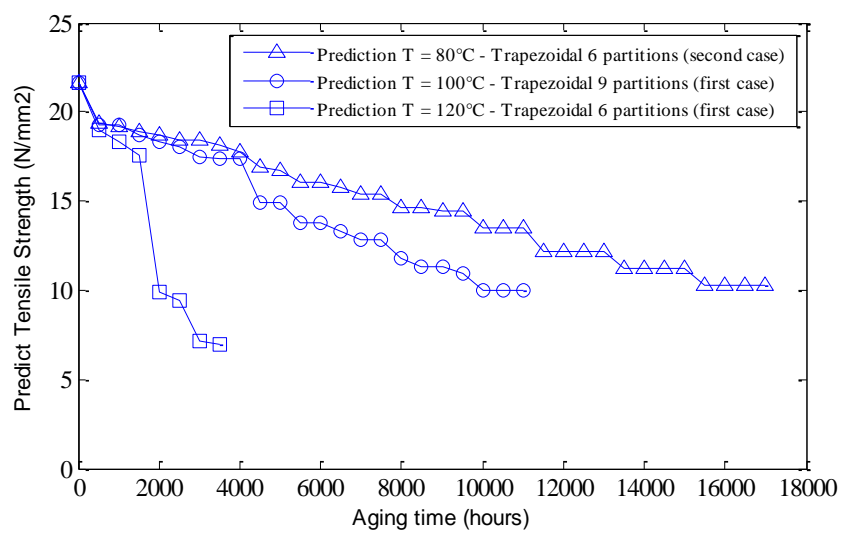

Figure 8

Prediction of tensile strength for different aging temperatures

In Figure 9, we have presented the lifetime endurance of the insulation, where we have reported the variation of aging time (in logarithmic) as a function of the reciprocal of absolute temperature [24].

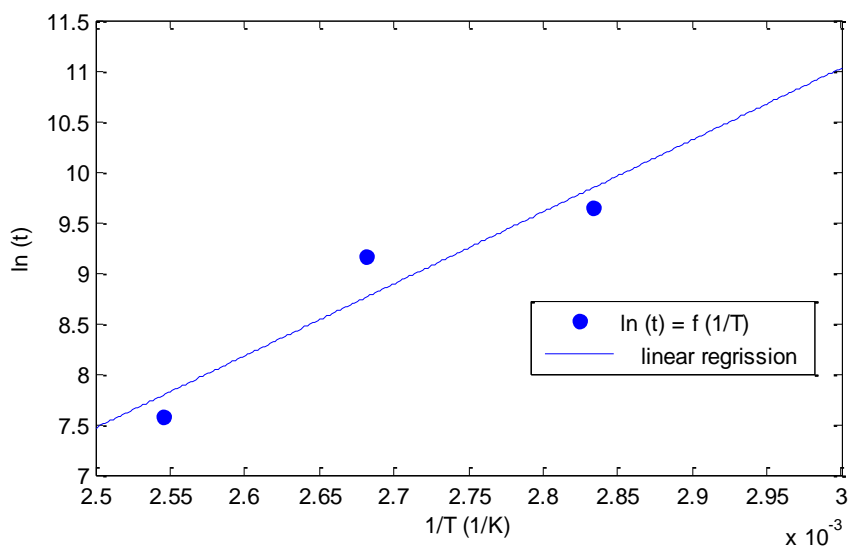

Figure 9

Variation of aging time logarithm vs reciprocal of absolute temperature

Table 6

Different values of aging times and temperatures for $50 \%$ end life criterion

\begin{tabular}{|c|c|c|c|}
\hline $\begin{array}{c}\text { Aging time } \\
\text { (hours) }\end{array}$ & $\begin{array}{c}\text { Logarithm of time } \\
\ln (\mathrm{t})\end{array}$ & $1 / \mathrm{T}\left(\mathrm{K}^{-1}\right)$ & $\mathrm{T}\left({ }^{\circ} \mathrm{C}\right)$ \\
\hline 1939 & 7,5699 & 0,002545 & 120 \\
\hline 9552 & 9,1645 & 0,002681 & 100 \\
\hline 15447 & 9,6452 & 0,002833 & 80 \\
\hline 20000 & 9,9035 & 0,002842 & 78,82 \\
\hline
\end{tabular}




\section{Conclusions}

The process of aging of the insulation material can be monitored by several techniques based on numerous experimental studies or modelling aspect. To predict the mechanical behaviour of the insulation, a long time is needed to have a complete test database enough to give a good prediction.

In this paper, a new approach based on an expert system of fuzzy logic modelling was proposed to predict the behaviour of XLPE used as insulation in high voltage cables. From the obtained results, it can be concluded that fuzzy logic by its flexibility in establishment helped us to model and predict the XLPE properties in a simple way. This intelligent modelling technique can be considered as an alternative solution for conventional methods since it avoids mathematical modelling especially for complex systems. The use of this method proves a great effectiveness.

Several Fuzzy model parameters have been also studied in this paper. It seems that the trapezoidal function form presents linguistic variables in a best way and gives very close results to experimental results with quite small error rates and in relatively short time. Finally, we can say that it is economic to apply fuzzy logic in investigations on the HV insulation since it allows us to reduce both tests time and costs in laboratory experiments.

\section{References}

[1] P. Hyvönen, B. Oyegoke, M. Aro: Diagnostics and Testing of High Voltage Cable Systems, Helsinki University of Technology, High Voltage Institute, Finland 2003

[2] A. R. Yazdandoust, F. Haghjoo, S. M. Shahrtash: Insulation Status Assessment in High Voltage Cables Based on Decision Tree Algorithm, IEEE Electrical Power \& Energy Conference, 2008

[3] A. Tzimas, S. Rowland, L. A. Dissado, M. Fu, U. H. Nilsson: Effect of Long-Time Electrical and Thermal Stresses upon the Endurance Capability of Cable Insulation Material, IEEE Trans. Dielect. Electri. Insul., Vol. 16, No. 5, pp. 1436-1443, October 2009

[4] T. Seguchia, K. Tamura, T. Ohshima, A. Shimada, H. Kudoh: Degradation Mechanisms of Cable Insulation Materials During Radiation Thermal Ageing in Radiation Environment, Radiation Physics and Chemistry, Vol. 80, pp. 268-273, 2011

[5] J. Li, X. Zhao, G. Yin, S. Li, J. Zhao, B. Ouyang: The Effect of Accelerated Water Tree Ageing on the Properties of XLPE Cable Insulation, IEEE Trans. Dielect. Electri. Insul., Vol. 18, No. 5, pp. 15621569, October 2011

[6] H. C. Chen, F. C. Gu, M. H. Wang: A Novel Extension Neural Networkbased Partial Discharge Pattern Recognition Method for High-Voltage 
Power Apparatus, Expert Systems with Applications, Vol. 39, pp. 34233431, 2012

[7] L. Mokhnache, A. Boubakeur: Comparison of Different Back-Propagation Algorithms Used in the Diagnosis of Transformer Oil, IEEE, Ann. Rep. Conf. Electrical Insulation and Dielectric Phenomena (CEIDP), pp. 224247,2002

[8] Y. Bourek, L. Mokhnache, N. Nait Said, R. Kattan: Determination of Ionization Conditions Characterizing the Breakdown Threshold of a PointPlane Air Interval Using Fuzzy Logic, Electric Power Systems Research, Vol. 81, pp. 2038-2047, 2011

[9] L. Bessissa, L. Boukezzi, D. Mahi, A. Boubakeur: Modelling and Prediction of HV Insulation Cables Behaviour under Thermal Aging: Use of Fuzzy logic Approach, Third International Meeting on Dielectric Materials IMDM'3, Monastir - Tunisia, November 13-18, 2011

[10] L. Bessissa, L. Boukezzi, Z. Turki, D. Mahi, A. Boubakeur: Influence of the Variation of Fuzzy Algorithms Parameters on the Quality of HV Cable Insulation Properties Modeling Subjected to Thermal Aging, $5^{\text {th }}$ International Workshop on Impedance Spectroscopy IWIS'5, ChemnitzGermany, November 26-28, 2012

[11] I.E.C. 540: Test Methods for Insulation and Sheaths of Rigid and Flexible Electrical Cables (elastomeric and thermoplastic blends) 1983 (in French)

[12] L. Boukezzi: Influence of Thermal Aging on the Properties of Cross-linked Polyethylene Insulation used in High Voltage Cables Ph.D. Thesis ENP of Algiers Algeria, June 2007

[13] I.E.C. 502: Power Cables Insulated with Solid Dielectrics for RATED Voltages from $1 \mathrm{kV}$ to $30 \mathrm{kV}$, Edition 1997 (in French)

[14] L. Zadeh: Fuzzy Sets, Inform Control, 8: pp. 338-53, 1967

[15] M. Sarıdemir, I. B. Topçu, F. Özcan, M.H. Severcan: Prediction of LongTerm Effects of GGBFS on Compressive Strength of Concrete by Artificial Neural Networks and Fuzzy Logic, Construction and Building Materials, 2008

[16] Z. Sen: Fuzzy Algorithm for Estimation of Solar Irradiation from Sunshine Duration, Sol Energy, Vol. 63, No. 1, pp. 39-49, 1998

[17] W. Pedrycz: Fuzzy Control and Fuzzy Systems Research Studies, John Wiley and Sons, N.Y. 1989

[18] R. Gayakwad: Optimized Fuzzy Logic for Motion Control, Acta Polytechnica Hungarica, Vol. 7, No. 5, pp. 161-168, 2010

[19] K. M. Passino, S. Yurkovich: Fuzzy control, Addison-Wesley, 1998 
[20] DWC. Ho, P.A. Zhang, J. Xu: Fuzzy Wavelet Networks for Function Learning, IEEE Trans Fuzzy Syst, Vol. 9, No. 1, pp. 200-11, 2001

[21] K. Nagy, S. Divéki, P. Odry, M. Sokola: A Stochastic Approach to Fuzzy Control, Acta Polytechnica Hungarica, Vol. 9, No. 6, pp. 29-48, 2012

[22] R. Bakhtyar, A. Y. Bakhtiary, A. Ghaheri: Application of Neuro-Fuzzy Approach in Prediction of Runup in Swash Zone, Applied Ocean Research, Vol. 30, pp. 17-27, 2008

[23] J. SR. Jang. ANFIS: Adaptive-Network-based Fuzzy Inference Systems, IEEE Trans Syst Man Cybern, Vol. 23, No. 3, pp. 665-85, 1993

[24] B. Fallou: New Rules for the Determination of Materials Thermal Endurance, R.G.E., Vol. 83, No. 7/8, pp. 445-52, July/August 1974

[25] L. Boukezzi, M. Nedjar, L. Mokhnache, M. Lallouani, A. Boubakeur: Thermal Aging of Cross-linked Polyethylene, Annales de Chimie, Science des Matériaux, Vol. 31, No. 5, pp. 561-569, 2006 